OPEN ACCESS

Edited by:

Lin-Hua Jiang,

University of Leeds, United Kingdom

Reviewed by:

Nicholas Veldhuis,

Monash University, Australia

Krishna Rajarathnam,

University of Texas Medical Branch

at Galveston, United States

*Correspondence:

Yong Ho Kim

euro16@gachon.ac.kr

Chul-Kyu Park

pck0708@gachon.ac.k

${ }^{\dagger}$ These authors have contributed

equally to this work

Specialty section:

This article was submitted to

Signaling,

a section of the journal

Frontiers in Cell and Developmental

Biology

Received: 16 July 2020 Accepted: 20 November 2020 Published: 10 December 2020

Citation:

Roh J, Go EJ, Park J-W, Kim YH and Park C-K (2020) Resolvins: Potent Pain Inhibiting Lipid Mediators via Transient Receptor Potential

Regulation.

Front. Cell Dev. Biol. 8:584206. doi: 10.3389/fcell.2020.584206

\section{Resolvins: Potent Pain Inhibiting Lipid Mediators via Transient Receptor Potential Regulation}

\author{
Jueun Roh't, Eun Jin Go ${ }^{1 \dagger}$, Jin-Woo Park', Yong Ho Kim ${ }^{1 *}$ and Chul-Kyu Park ${ }^{1 *}$ \\ 1 Gachon Pain Center and Department of Physiology, College of Medicine, Gachon University, Incheon, South Korea, \\ ${ }^{2}$ Department of Periodontology, School of Dentistry, Kyungpook National University, Daegu, South Korea
}

Chronic pain is a serious condition that occurs in the peripheral nervous system (PNS) and the central nervous system (CNS). It is caused by inflammation or nerve damage that induces the release of inflammatory mediators from immune cells and/or protein kinase activation in neuronal cells. Both nervous systems are closely linked; therefore, inflammation or nerve damage in the PNS can affect the CNS (central sensitization). In this process, nociceptive transient receptor potential (TRP) channel activation and expression are increased. As a result, nociceptive neurons are activated, and pain signals to the brain are amplified and prolonged. In other words, suppressing the onset of pain signals in the PNS can suppress pain signals to the CNS. Resolvins, endogenous lipid mediators generated during the resolution phase of acute inflammation, inhibit nociceptive TRP ion channels and alleviate chronic pain. This paper summarizes the effect of resolvins in chronic pain control and discusses future scientific perspectives. Further study on the effect of resolvins on neuropathic pain will expand the scope of pain research.

Keywords: resolvins, TRP channel, pain, inflammatory, neuropathy

\section{INTRODUCTION}

The International Association for the Study of Pain defines pain as an unpleasant sensory and emotional experience associated with, or resembling that associated with, actual or potential tissue damage (Raja et al., 2020). Pain is classified into three types according to its cause. First, the pain generated when individuals are exposed to noxious stimuli such as extreme temperatures or sharp objects, is called nociceptive pain. Generally, pain is considered to be a negative feeling that needs to be eliminated, but nociceptive pain is protective and essential. It protects us from being injured by a hostile environment (Scholz and Woolf, 2002; Woolf, 2010). Second, inflammatory pain is caused by activation of the immune system, and it is also protective. Inflammation following tissue injury or infection is characterized by releasing proinflammatory mediators including bradykinin, prostaglandins, nerve growth factors (NGF), proinflammatory cytokines, and chemokines from immune cells. These mediators bind to pain receptors expressed in nociceptors (Woolf, 2010; Lim et al., 2015). Pathological pain is not protective and results from abnormal functioning of the nervous system. This can be categorized into two types depending on the presence of damage; one 
is neuropathic pain, which occurs after nerve damage; the other is dysfunctional pain, which can occur in the absence of inflammation or nerve damage (Woolf, 2010).

Inflammation and nerve damage can induce neural plasticity that results from changes in the nervous system and reduces the pain threshold. Therefore, inflammatory pain and neuropathic pain are characterized by peripheral nociceptor sensitization, arising from spontaneous nociceptor activity, hyperalgesia, and allodynia. Transient receptor potential (TRP) ion channels that are expressed in nociceptors are persistently activated by inflammatory mediators during the pathological state. TRPV1 and TRPA1 are notable nociceptive TRP ion channels, and activation of these channels can stimulate hyperexcitability of the peripheral nociceptors that transmit pain signaling to the central nervous system (CNS) (Scholz and Woolf, 2002; Patapoutian et al., 2009; Lim et al., 2015; Jardin et al., 2017; Mourot et al., 2018). Inflammatory pain includes pain from a surgical wound or an inflamed joint, while the etiology of neuropathic pain includes diabetes and chemotherapy-related peripheral neuropathy.

Resolvins (RVs) are lipid mediators that are biosynthesized from omega-3 polyunsaturated fatty acids (PUFAs) that are abundant in marine oil. Aspirin/cyclooxygenase-2 (COX-2) and other enzymes convert omega-3 docosahexaenoic acid (DHA) and eicosapentaenoic acid (EPA) to resolvin D and E through multiple mechanisms (Serhan et al., 2002). These lipid mediators are generated during the resolution phase of acute inflammation and not only terminate inflammation but also alleviate pain (Ariel and Serhan, 2007; Xu et al., 2010). The Ji lab found that the resolvin series has an analgesic effect on various types of inflammatory pain models through regulation of TRP channels (Xu et al., 2010; Park et al., 2011b).

This review will highlight TRP channels, with an emphasis on TRPV1 and TRPA1, as therapeutic targets for the resolution of both inflammatory and neuropathic pain using resolvins. To address this, pain and TRP are first described prior to resolvins. At the end, the importance of further study on the role of resolvins in neuropathic pain via TRP regulation is also suggested.

\section{CONNECTIVITY OF PERIPHERAL AND CENTRAL NERVOUS SYSTEMS IN PAIN PATHWAYS}

\section{Anatomical Pain Pathway}

Primary afferent neurons are pseudounipolar neurons that have one axon from the soma and bidirectional branches at the axon terminals (Amir and Devor, 2003; Gibson and Ma, 2011). The branches project to the peripheral (target organ) and central projection (spinal cord), respectively (Gibson and Ma, 2011), and transduce sensory information (mechanical, thermal, and chemical) from the peripheral to the central nervous system (Hasegawa et al., 2007).

Primary afferent nerve fibers are classified by fiber diameter or myelination and project to distinct laminae in the dorsal horn of the spinal cord. Fiber diameter and myelination are related to conduction velocity. Myelinated $A \alpha$ and $A \beta$ fibers have a large diameter and fast conduction velocity. Rapidly conducting $\mathrm{A} \beta$ fibers conduct proprioception and touch sensations and project to deeper laminae: III, IV, and V. However, studies have revealed that some $A \beta$ fibers also are related to pain regulation (Xu et al., 2015; Tashima et al., 2018; Nagi et al., 2019). While thinly myelinated $\mathrm{A} \delta$ fibers and unmyelinated $\mathrm{C}$ fibers both have relatively small diameters, the former have faster conduction velocities than do the latter. A $\delta$ fibers conduct touch, pressure, and "first" pain signals to laminae I and V. Slowly conducting $\mathrm{C}$ fibers respond to heat and mechanical stimuli and conduct "second" pain related signals to lamina I (peptidergic C fibers) and lamina II (non-peptidergic C fibers) (Julius and Basbaum, 2001; Furue et al., 2004; Basbaum et al., 2009). Unmyelinated $\mathrm{C}$ fibers and thinly myelinated $\mathrm{A} \delta$ fibers are activated by highintensity stimuli (Ji and Woolf, 2001). The activation of A $\delta$ fibers evokes sharp and pricking pain, whereas the activation of $\mathrm{C}$ fibers evokes a burning sensation (Bishop, 1980).

Different pathways to the brain carry different types of sensory information. Pain and heat signals from $\mathrm{C}$ and $\mathrm{A} \delta$ fibers in the superficial dorsal horn cross the midline and ascend the spinal cord. Then, sensory information is carried to the brain through the lateral spinothalamic tract (Melzack and Wall, 1962; Basbaum et al., 2009). On the other hand, proprioception and touch signals do not cross the spinal cord but ascend to the brain through the anterior spinothalamic tract (Basbaum et al., 2009).

\section{Central Sensitization}

Central sensitization involves the increased responsiveness of nociceptive neurons in the CNS that can be generated from intense and repeated peripheral inputs. Sensitized C-fibers lead to the increased release of neurotransmitters such as glutamate, substance P (SP), calcitonin gene-related peptide (CGRP), and brain-derived neurotrophic factor (BDNF) into central terminals of the spinal cord dorsal horn (postsynaptic). Released neurotransmitters bind to their receptors, including $N$-methyl-D-aspartate receptors (NMDAR), $\alpha$-Amino-3-hydroxy-5-methyl-4-isoxazolepropionic acid receptors (AMPAR), metabotropic glutamate receptors (mGluR), neurokinin-1 receptors (NK-1R), and tropomyosin receptor kinase (Trk) receptors, on the postsynaptic neurons. These series of processes induce hyperactive/hyperexcited states in the postsynaptic neurons and result in hyperalgesia (an abnormal increase in pain sensitivity from painful stimuli), allodynia (pain caused by non-painful stimuli), and the expansion of the receptive fields of nociceptors (Hylden et al., 1989; Latremoliere and Woolf, 2009; Woolf, 2011). Additionally, peripheral injury can redistribute the central terminals of myelinated afferents and induce pain by non-painful afferents (Woolf et al., 1992; Tashima et al., 2018; Nagi et al., 2019). This process seems similar to peripheral sensitization in so far as it also results in hyperalgesia and allodynia but differs in the range of sites that cause the resulting pain. Peripheral sensitization occurs when nociceptors are exposed to inflammatory mediators and damaged tissue. Consequently, the abnormal pain sensation 
prompted by peripheral sensitization is limited to inflamed or damaged sites. Hence, this phenomenon can function to protect sites of injury. By contrast, central sensitization can induce pain either in sites where inflammation or injury has already been resolved or without no obvious inflammation or injury.

Intracellular $\mathrm{Ca}^{2+}$ is important to initiating central sensitization. Under normal conditions, the pores of NMDARs are blocked by $\mathrm{Mg}^{2+}$. However, glutamates released from presynaptic buds dislodge $\mathrm{Mg}^{2+}$ and allow $\mathrm{Ca}^{2+}$ to enter the cytosol. Further, activation of the group I mGluRs (mGluR1 and 5) opens the $\mathrm{Ca}^{2+}$ channels on the endoplasmic reticulum (ER). Intracellular $\mathrm{Ca}^{2+}$ activates protein kinase $\mathrm{C}$ (PKC), PKA, and calmodulin-dependent protein kinase II (CaMKII). These kinases phosphorylate ion channels and glutamate receptors, and their properties are rapidly changed. PKC phosphorylates Ser831 on the GluR1 of AMPAR, Ser880 on GluR2, and Ser896 on NR1 of the NMDAR subunit. PKA phosphorylates Ser890 and Ser897 on NR1 and Ser845 on GluR1. CaMKII phosphorylates Ser1303 on NR2B and Ser831 on GluR1 (Suo et al., 2013; Ji et al., 2018). These processes correspond to the early, phosphorylation-dependent phase of central sensitization in which extracellular signalregulated protein kinase (ERK) is important to sustain central sensitization. The activation of ERK stimulates increases in the transcription of several genes, such as c-Fos, NK1, TrkB, and Cox-2, the phosphorylation of NMDAR and Ser616 on Kv4.2, and the insertion of AMPAR into the membrane. Together, these events increase neuronal excitability in the spinal cord (Ji and Woolf, 2001; Pace et al., 2018).

\section{TRP CHANNEL AND PAIN}

Unpleasant and painful sensations signal organisms to subsequently avoid these situations, allowing the organisms to survive noxious insults and injuries. Such noxious stimuli are detected by nociceptors, specialized peripheral sensory neurons that send the threatening signals to the spinal cord and the brain. If a stimulus is intense enough to reach the noxious range, ion channels expressed in the nociceptors are activated and generate action potentials. Ion channels called TRP channels are considered to play an important role in transducing noxious thermal, chemical, and mechanical stimuli.

The TRP channels were first discovered in the eyes of a TRP-mutant Drosophila melanogaster, where the mutant fly displayed a transient abnormal response to a bright light, while wild type flies showed a sustained response (Cosens and Manning, 1969). Later, TRP channels in mammalian were introduced with an extended protein family comprising more than 30 distinct subtypes (Ramsey et al., 2006). The TRP family can be distinguished into 6 members: TRPV (vanilloid), TRPA (ankyrin), TRPM (melastatin), TRPC (canonical), TRPP (polycystin), and TRPML (mucolipin) (Chung and Caterina, 2007). These TRP families are similar in architecture, having six putative transmembrane domains with cytoplasmic amino and carboxyl termini, although they differ in amino-acid conservation. Among these members of TRP family, at least six subtypes, including TRPV1-4, TRPA1, and TRPM8, are closely related to painful thermal, chemical, and mechanical stimuli evoking nociceptive pain (Patapoutian et al., 2009; Dai, 2016). Intracellular $\mathrm{Ca}^{2+}$ concentration increases in response to stimuli that are specific to certain TRP channels, such as $\mathrm{Ca}^{2+}$ entry channels (Zheng, 2013). TRP channels also stimulate intracellular signaling pathways (e.g., PKC activity) and cause transcriptional changes, all of which promote the expression and release of pro-inflammatory peptides such as SP and CGRP (Veldhuis et al., 2015). Moreover, G protein-coupled receptors (GPCRs) are located in the plasma membrane along with TRP channels and are responsible for the central transduction of painful signals from the periphery nociceptors. These GPCRs are activated by noxious stimuli from the extracellular environment and control TRP channel activity through several mechanisms, wherein the G-protein subunits stimulate second messenger kinases [e.g., cyclic adenosine monophosphate (cAMP)-dependent protein kinase A, phospholipase C (PLC), PKC] (Veldhuis et al., 2015).

\section{TRPV1 as Thermal Sensor}

Transient receptor potential channels specifically related to pain and thermosensation were first suggested when the capsaicin receptor, TRPV1, was cloned from a rodent dorsal root ganglia (DRG) in 1997 and was reported as a non-selective cation channel exhibiting high calcium permeability (Caterina, 2007). TRPV1 is mainly expressed in small diameter neurons in the DRG and trigeminal ganglion (TG). TRPV1 is activated by both noxious heat $\left(\geq 43^{\circ} \mathrm{C}\right)$ and capsaicin, the pungent ingredient of chili peppers, triggering a sensation of burning pain. In addition to capsaicin and noxious heat, TRPV1 is also activated by spider toxin (Siemens et al., 2006) and low $\mathrm{pH}$ (protons) (Caterina et al., 1997). Therefore, TRPV1 is defined as a polymodal receptor (Clapham, 2003). Moreover, certain studies revealed that TRPV1-deficient mice had a complete loss of physiological and behavioral responses to capsaicin, along with significant impairment in responses to noxious heat and mechanical stimuli (Caterina et al., 2000; Davis et al., 2000; Bolcskei et al., 2005). However, other studies reported that TRPV1 null mice had no differences in sensitivity to acute noxious heat compared to wild type mice (Davis et al., 2000; Woodbury et al., 2004). This suggests that TRPV1 is not solely responsible for the sensation of noxious heat, indicating the presence of other possible compensatory mechanisms.

\section{TRPA1 as a Chemical and Thermal Sensor}

Another non-selective cation channel of the TRP family subtypes, TRPA1, is also found to be critical in nociception. TRPA1 is highly co-expressed with TRPV1 in small-diameter nociceptors in the DRG and TG and can be influenced by TRPV1 (Salas et al., 2009; Staruschenko et al., 2010). TRPA1 is a polymodal receptor, like TRPV1 (Story et al., 2003; Dai et al., 2007). TRPA1 is activated by a variety of noxious stimuli that induce acute painful burning or stinging sensations including chemicals, 
such as mustard oil (isothiocyanates), garlic (allicin), and cinnamon oil (cinnamaldehyde) (Bandell et al., 2004; Jordt et al., 2004; Bautista et al., 2005; Macpherson et al., 2005). These chemicals are all electrophilic and activate TRPA1 by covalent modification of cysteine residues in the channel, suggesting that the reactivity of such chemicals is not necessarily dependent on its structure (Hinman et al., 2006; Macpherson et al., 2007). In TRPA1 knockout mice studies, those chemicals showed reduced nociceptive pain behavior (Macpherson et al., 2007; McNamara et al., 2007), indicating TRPA1 as a key detector of chemical damage. Additionally, TRPA1 has also been suggested to detect noxious cold stimuli $\left(<15^{\circ} \mathrm{C}\right)$ (Story et al., 2003; Sawada et al., 2008), even though studies of TRPA1-deficient mice showed discordant results (Bandell et al., 2004; Jordt et al., 2004; Zurborg et al., 2007; Karashima et al., 2009).

\section{TRP CHANNELS IN INFLAMMATORY PAIN CONDITIONS}

Depending on pathological conditions such as inflammation (inflammatory pain) or nerve injury (neuropathic pain), changes occur in the expression of TRP channels and their function, including transcriptional and translational regulation and post-translational alteration (Patapoutian et al., 2009). As mentioned above, inflammatory pain is generated from the activation and sensitization of nociceptive pain signaling in the form of a reduced threshold and an increased responsiveness of nociceptors. Three cellular and molecular mechanisms have been suggested in the development of inflammatory pain involved in TRP channels. First, TRP channel expression increases in the sensory neurons either transcriptionally or post-translationally during inflammation. For instance, the activation of C-C chemokine receptor type 2 (CCR2) by the macrophage inflammatory protein-1 $\alpha$ (MIP-1 $\alpha /$ CCL3) increases the transcription of TRPV1 and TRPA1 (Jung et al., 2008); i.e., TRPV1 levels in peripheral terminal or nociceptors are increased in order to maintain the inflammatory heat hypersensitivity (Ji et al., 2002). TRPA1 in DRG neurons is also upregulated by peripheral inflammation transcriptionally, leading to inflammatory cold hyperalgesia (Obata et al., 2005). In other words, the increase in expression and the oxidative products from tissue damage and inflammation led to a drastic decrease in the activation threshold, thereby increasing sensitivity to noxious stimuli (via peripheral sensitization) (Hucho and Levine, 2007). Second, translocation of functional TRP channels from the cytoplasm to the plasma membrane is induced following the activation of second-messenger pathways and subsequent post-translational modification (e.g., channel phosphorylation or glycosylation) (MorenillaPalao et al., 2004; Nguyen et al., 2005; Zhang et al., 2005). Third, channel phosphorylation as a disinhibition mechanism with inflammatory mediators might cause channel structure alteration and functionally enhance the channel sensitivity (Dai et al., 2007). Tumor necrosis factor (TNF)- $\alpha$ increases the frequency, not the amplitude, of spontaneous excitatory postsynaptic currents (sEPSCs) in wild type mice but not in
TRPV1 KO mice (Park et al., 2011a). Importantly, studies conducted using knockout mice lacking TRPV1 showed that the development of inflammatory thermal hyperalgesia became defective (Keeble et al., 2005; Barton et al., 2006). This suggests that TRPV1 is a key component of the mechanism in which inflammation causes thermal hyperalgesia and pain hypersensitivity (Caterina et al., 2000; Davis et al., 2000; Bolcskei et al., 2005; Basbaum et al., 2009). In addition to TRPV1, TRPA1-deficient mice studies also showed markedly reduced development of hyperalgesia in response to inflammationrelated chemicals that were injected such as formalin and bradykinin (Bautista et al., 2006; McNamara et al., 2007; Andersson et al., 2008).

\section{TRP CHANNELS IN NEUROPATHIC PAIN CONDITIONS}

Physiological changes such as increasing the local $\mathrm{Ca}^{2+}$ ion concentration in primary sensory neurons or in the spinal cord owing to nerve injury consequently affect signal processing in the CNS, evoking neuropathic pain (Fernyhough and Calcutt, 2010). When neuropathic pain impulses are transmitted from the periphery to the CNS, nociceptive transmitters such as SP are released by exocytosis from the primary sensory terminals in the spinal dorsal horn, where TRP channels are mediated by voltage-dependent $\mathrm{Ca}^{2+}$ channels (Verkhratsky and Fernyhough, 2008).

After nerve damage, expression in TRP channel changes dynamically in sensory neurons, and different TRP channels are involved in the management of neuropathic pain. In the spinal nerve section model, the expression of TRPV1 mRNA is reduced in the axotomized ganglia, suggesting loss of trophic support after the injury (Michael and Priestley, 1999). In L5 spinal nerve ligation model, TRPV1, TRPA1, and TRPM8 are upregulated in uninjured L4 somata (Hudson et al., 2001; Obata et al., 2005). It has been suggested that the injured neurons might release growth factors and neurotransmitters into the surrounding region, causing an increase in the excitability of nearby uninjured spared neurons (Fukuoka et al., 2001; Sexton et al., 2014). Vilceanu et al. (2010) revealed that the proportion of TRPV1-expressing DRG neurons was increased and its TRPV1 function was improved after nerve injury induced by spinal nerve ligation (SNL). Moreover, sciatic nerve transection in rats results in up-regulation of TRPV1 at the central terminals of the primary afferent neurons in the spinal cord, increased release of inflammatory neuropeptides such as calcitonin generelated peptide and SP from the presynaptic central terminals, and enhanced glutamatergic neurotransmission (Kanai et al., 2005; Lappin et al., 2006; Lee and Kim, 2007; Spicarova et al., 2011). Both TRPV1 and TRPA1 are involved in peripheral neuropathy and neuropathic pain induced by chemotherapeutic agents such as cisplatin, oxaliplatin, and paclitaxel. Inhibition of TRPA1 function eliminates mechanical as well as cold allodynia induced by cisplatin and oxaliplatin, which are most commonly used for chemotherapy (Baron, 2009; Nassini et al., 2011; Zhao et al., 2012). Paclitaxel chemotherapy mediates 
neuropathic pain behaviors by the release of mast cell tryptase to activate the protease-activated receptor 2 (PAR 2), which then sensitizes TRPV1, TRPV4, and TRPA1 via PLC, PKC, and PKA signaling (Chen et al., 2011); it also enhances the TRPV1 mRNA transcripts and TRPV1 protein in small-to-medium diameter DRG neurons (Hara et al., 2013). Additionally, in neuropathic pain induced by a chronic constriction injury model, inhibition of TRPA1 function also diminishes cold allodynia (Hara et al., 2013).

Certain pro-inflammatory lipid mediators [e.g., leukotrienes (LTs) and prostaglandins (PGs)] in the spinal cord reportedly contribute to neuropathic pain. Of interest, a growing evidence has established that microglial activation has emerged as key players in maintaining pain hypersensitivity in the dorsal horn. Together, the activation of microglia induces dramatic changes including an intracellular signaling molecules [e.g., mitogenactivated protein kinases (MAPKs)], leading to increase the production of pro-inflammatory lipid mediators in the microglia. Following peripheral nerve injury, adenosine triphosphate (ATP) is known to be released from the primary afferent central terminals in the spinal cord, and studies have shown that expression of the purinergic P2 (P2X) receptors was upregulated in microglia to be able to detect extracellular ATP in the spinal cord (Tsuda et al., 2003; Ulmann et al., 2008). LTs are a group of lipid mediators derived from arachidonic acid (AA) which is converted into leukotriene A4 (LTA4) via the 5-lipoxygenase (5-LO) pathway in microglia. LTA4 is then enzymatically converted into LTB4 (Noguchi and Okubo, 2011). In the rat model of spared nerve injury (SNI), LTB4 was expressed in both the spinal neurons and microglia along with LTB4 receptor 1 (BLT1), and the BLT1 was expressed in the spinal neurons. The effect of LTs on neuropathic pain behaviors was identified by intrathecal administration of a 5-LO inhibitor that attenuated the mechanical hypersensitivity caused by SNI surgery (Okubo et al., 2010). Okubo and researchers also found that the increase of 5-LO in spinal microglia was reduced on treatment with an p38 MAPK inhibitor, but not mitogen-activated protein kinase (MEK) inhibitor, indicating that the p38 MAPK pathway is crucial in the generation of neuropathic pain (Figure 1). While BLT1 binds LTB4 as its agonist, resolvin $\mathrm{E} 1$ and $\mathrm{E} 2$ are considered as endogenous receptor antagonists for BLT1. A previous study showed that intrathecal pre-treatment of RvE1 attenuated neuropathic pain by modulating microglial activation in the spinal cord (Xu et al., 2013); thus, there may be an association of BLT1 with RvE1 and E2. In the context of AA metabolites, it is also known to be metabolized into the epoxygenase metabolite, 5,6-EET, which directly activates TRPV4 channels (Vriens et al., 2004). However, not all AA-derived mediators have pro-inflammatory action. Lipoxin A4 (LXA4) is an eicosanoid derived from AA through sequential actions of lipoxygenases, 15-LO and 5-LO; it is known to be an agonist for ALX/FPR2, acting as an endogenous "stop" signal in acute inflammation to switch into the resolution phase (Levy et al., 2001). Martini et al. showed that treatment with LXA4 modulated microglial activation and TNF$\alpha$ release via ALX/FPR2 receptors, thereby reducing neuropathic pain in rodents after spinal cord hemisection (Martini et al.,
2016). PG, a pro-inflammatory mediator synthesized from AA by the COX enzyme in microglia, has been identified as another factor in mechanical allodynia in an SNI model. PGH2 is synthesized from AA by the action of COX and serves as a substrate of the prostaglandin synthase enzymes for producing the bioactive prostaglandins, PGE2 and PGD2, which bind to the EP and DP receptors, respectively (Kanda et al., 2013). Like LTB4, p38 activation in spinal microglia induces the release of PGE2 (Ji and Suter, 2007). Nakayama et al. reported an increase in PGE2 concentration and activation of EP1 receptors in the spinal dorsal horn in the late phase after carrageenan-induced mechanical hyperalgesia in rats (Nakayama et al., 2002). Moreover, following peripheral injury, an increase in PGD2 was noted, which was subsequent to the upregulation of COX-1, and the intrathecal injection of DP2 receptor antagonists attenuated the mechanical allodynia (Kanda et al., 2013). The activation of both EP and DP receptor initiate G-protein coupling to increase intracellular concentration of $\mathrm{Ca}^{2+}$ or cAMP in the dorsal horn (Jang et al., 2020). Although evidence of the mechanisms of prostaglandin and its receptors have been accumulated, their role in neuropathic pain and the resolution strategy remain unknown.

Moreover, these pathways of pro-inflammatory lipid mediators contributing to neuropathic pathways has not been studied in the context of TRP regulation. Moreover, even though these findings do not involve TRP regulation, LTs and PGs might be implicated in neuropathic pain by acting like G-proteinmediated signal transducers to initiate second messenger systems, which in turn activate TRP channels (Figure 1). Interestingly, TRPV1 is found to be upregulated in the spinal cord dorsal horn in the chronic constriction injury (CCI) neuropathic pain model, indicating possible interaction between the receptors mentioned above (Kanai et al., 2005). Further research will contribute identifying the analgesic effect caused by those pro-inflammatory mediators on neuropathic pain.

Transient receptor potential channels are upregulated in order to manage hypersensitivity of both inflammatory and neuropathic pain at the site of inflammation and the remaining intact neurons close to the damaged nerve, respectively. However, different mediators and intracellular mechanisms of TRP channels are involved, depending on what type of pain is occurring. Hence, it is important to elaborate the role of TRP channels in the resolution of different types of pathological pain using resolvin, which will be discussed in detail next.

\section{RESOLVINS (ENDOGENOUS LIPID MEDIATORS) INHIBIT TRP CHANNELS}

\section{Lipid Mediators in Resolution of Acute Inflammation}

Acute inflammation is a host defense system, and its resolution may serve as a gateway to chronic inflammation. In health status, inflammatory responses are self-limited, with many cell types and tissues involved in initiation and termination of acute inflammation (Serhan, 2007). Tissue injury or infection 
triggers the release of a train of signals, including damageassociated molecular patterns (DAMPs), pathogen-associated molecular patterns (PAMPs), lipid mediators and chemokines, such as formylmethionyl-leucyl-phenylalanine (fMLP), ATP, high mobility group box-1 (HMGB1), F-actin, N-glycan, LTB4, CCR1 ligands, chemokine (C-X-C motif) ligand (CXCL) 2, and CXCL8, from injury sites (McDonald and Kubes, 2010; Selders et al., 2017; Peiseler and Kubes, 2019; Gong et al., 2020). Neutrophils move through the chemoattractant gradient, while the integrin molecules on neutrophil surface bind to integrin receptors on endothelial cells enabling their infiltration into the tissues. The infiltrated neutrophils remove pathogens via phagocytosis and release reactive oxygen species (ROS), degradative enzymes, microbicidal agents, and neutrophil extracellular traps (Metzemaekers et al., 2020). Neutrophils are the first defender against hazardous invaders, but their high numbers can induce excessive inflammation (Freire and Van Dyke, 2013). Since excessive inflammation is considered to be a component in many chronic diseases, such as vascular diseases, metabolic syndrome, neurological diseases, and many others, proper resolution of acute inflammation is important. (Serhan et al., 2015b). Resolution of acute inflammation was introduced as a passive process following disappearance of the chemoattractant and other chemical mediators, but Dr. Serhan's group uncovered endogenous lipid mediators in inflammatory exudate: resolvins, protectins, and maresins (Serhan et al., 2002; Serhan, 2014). These pro-resolving lipid mediators are often referred to as specialized pro-resolving mediators (SPMs) because they stimulate efferocytosis of polymorphonuclear leukocytes (PMNs) to facilitate complete removal of pathogens, recruit macrophages, attenuate activated neutrophil through NF- $\kappa$ B inhibition, and initiate the resolution phase of acute inflammation (Flower and Perretti, 2005; Lee et al., 2013; Francos-Quijorna et al., 2017; Yurdagul et al., 2017; Rymut et al., 2020).

\section{Biosynthesis of Resolvins}

Notable omega-3 fatty acids are alpha-linolenic acid (ALA), EPA, and DHA. In humans, ALA converts to EPA and DHA, but the conversion rate of ALA to EPA is 8-20\%, and that to DHA is 0.59\%, which are very low (Stark et al., 2008).

In vascular endothelial cells, EPA is converted into $18 \mathrm{R}-$ hydroperoxy-EPE (18-HpEPE) with aspirin/COX-2 or microbial p450. 18-HpEPE is converted to 5S(6)-epoxy-18-hydroxy-HEPE

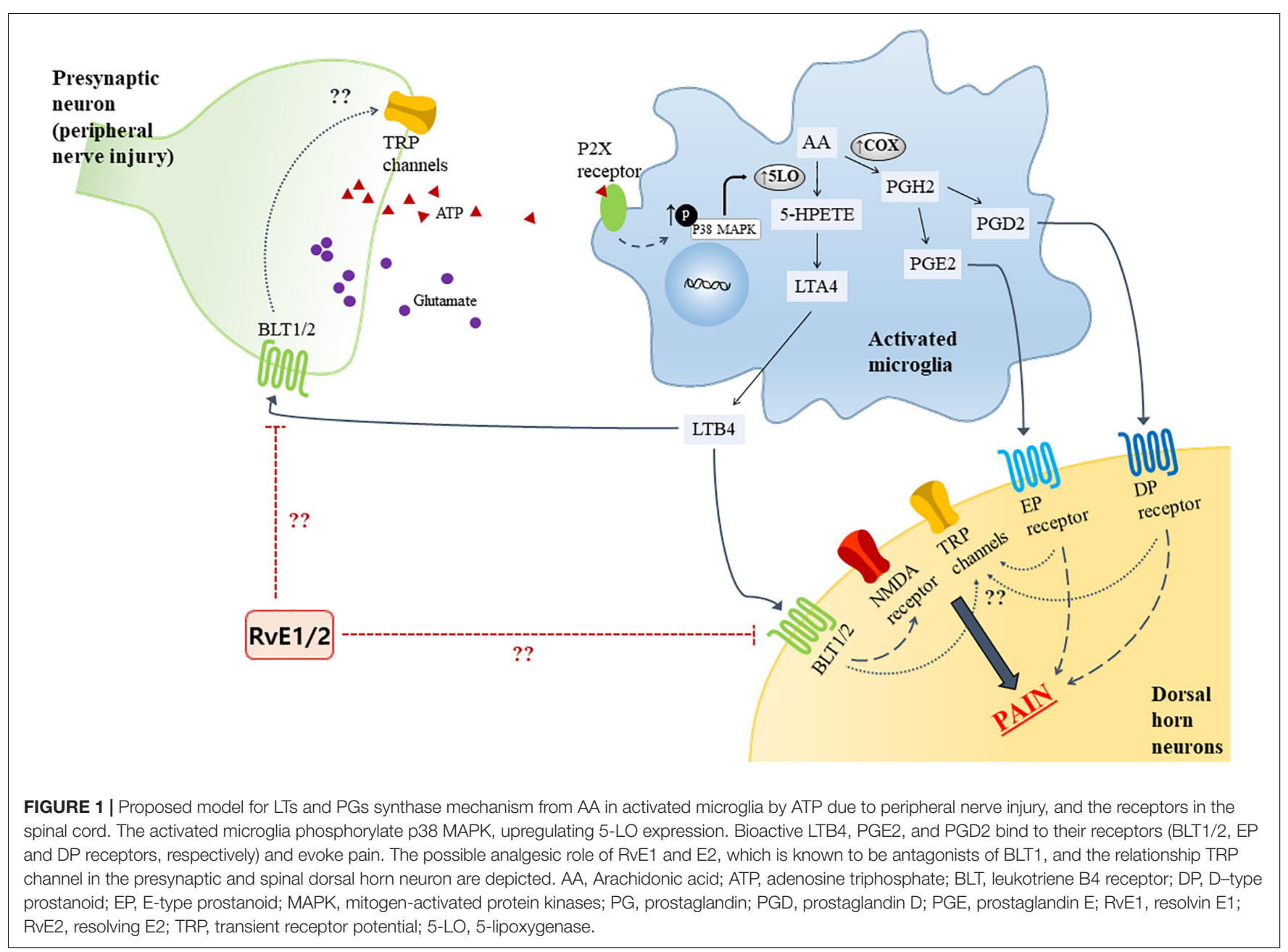




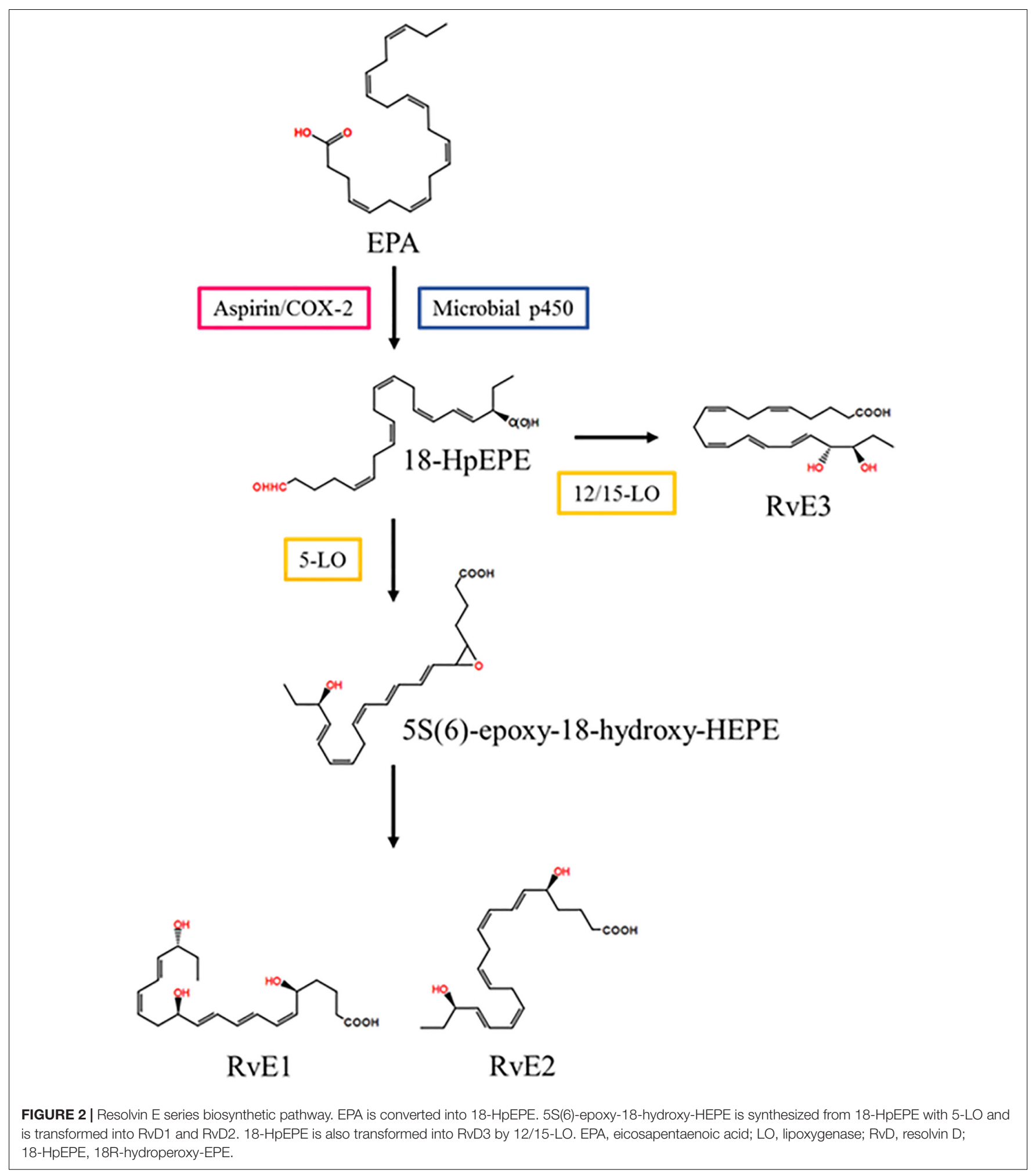

with 5- LO in leukocytes and then converted to resolvin E1 via enzymatic hydrolysis or to resolvin E2 via reduction (Serhan et al., 2015a). In eosinophils, 18-HpEPE is also converted to resolvin E3 via 12/15-LO pathways (Isobe et al., 2012) (Figure 2).
In exudates, resolvin D series are biosynthesized by PMNs or macrophages. DHA is metabolized to 17-hydroxydocosahexaenoic acid (17-HDHA) via 17hydroperoxydocosahexaenoic acid through 15-LO (Gleissman et al., 2010). 17-HDHA is converted to resolvin D1, D2, D3, D4, 


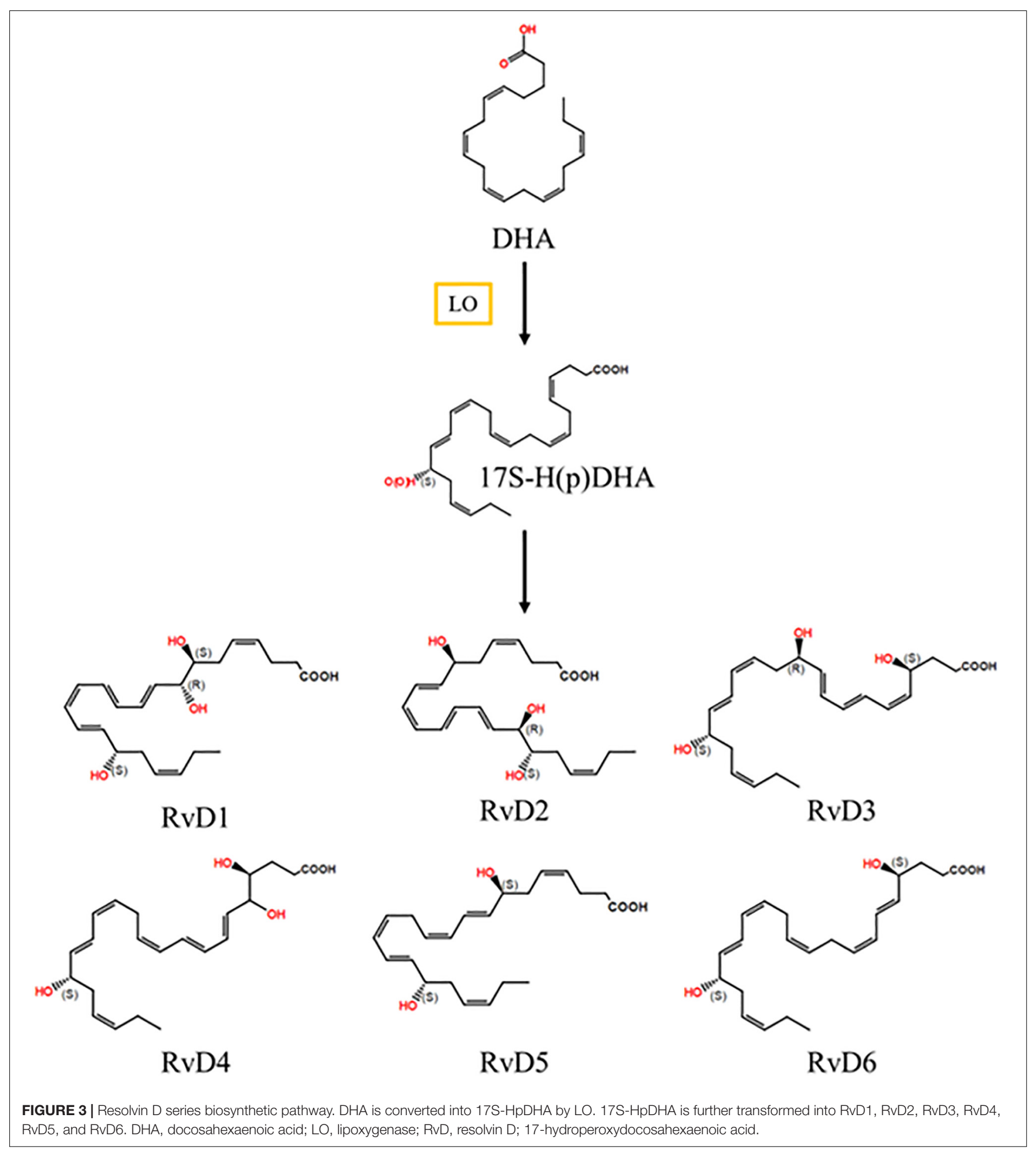

D5, and D6 through epoxidation and 5-LO (Figure 3). DHA is also metabolized with aspirin/COX-2, and then the aspirintriggered resolvin D (AT-RvD) series is formed (Lim et al., 2015; Serhan et al., 2015a; Serhan and Levy, 2018). AT-RvD3 is more potent than resolvin D3 in phagocytosis of 10 and $100 \mathrm{pM}$ zymosan (Dalli et al., 2013).
Since TRP channels are expressed in nociceptors where pain is generated, the roles of TRP channels in mediating pathological pain make them potential therapeutic targets for resolution. Until now, in addition to RvE1 and RvD1/AT-RvD1, more resolving family members have been biosynthesized: RvD2, RvD3, RvD4, and RvD5. RvE1, RvD1, and AT-TvD1 are already well-known 
agonists that resolve inflammation and inflammation-associated pain by mediating specific GPCRs [e.g., chemerin receptor23 (ChemR23) and GPR32], which are expressed by immune cells, glia cells, and neurons. This, in turn, reduces inflammation, glial activation, and spinal cord synaptic plasticity (Ji et al., 2011). Mounting evidence on resolvins as potent inhibitors for both inflammatory and neuropathic pain will be discussed with recent findings.

\section{Resolvin Receptors}

Resolvins can directly act on nociceptors but little is known about how resolvins inhibit TRP channels in neurons. Five GPCRs - ERV/ChemR23, BLT1, ALX/FPR2, DRV1/GPR32, and DRV2/GPR18 - are receptors for resolvin D and E series that play an important role in the modulation of the TRP channels (Pirault and Back, 2018) (Figure 4).

ChemR23, resolvin E1 and chemerin receptors (Herova et al., 2015) are co-expressed with TRPV1 in small sized-DRG neurons and in the spinal cord dorsal horn. Activation of chemR23 by resolvin E1 or chemerin blocked capsaicin-evoked spontaneous excitatory postsynaptic current frequency increases via the ERK pathway in the spinal cord dorsal horn, and resolvin E1 also blocked phosphorylation of ERK by capsaicin treatment in DRG neurons (Xu et al., 2010; Park et al., 2011b; Jo et al., 2016). ERK is a member of the mitogen-activated protein kinase superfamily of signaling pathways, an important kinase in painful conditions. In addition to capsaicin, noxious heat, cold, and prick upregulate the pERK intensity in neurons (Ji et al., 1999). In particular, pERK is upregulated in DRG and in the spinal cord in neuropathic pain models of partial sciatic nerve ligation (PSNL), SNL, CCI and diabetes (Seltzer et al., 1990; Song et al., 2005; Liu et al., 2012; Xu et al., 2014; Guo et al., 2019; Wang et al., 2020).

BLT1, LTB4 (agonist), and resolvin E1 (antagonist) receptor are co-expressed with TRPV1 in DRG neurons (Andoh and Kuraishi, 2005; Serhan and Chiang, 2013). LTB4 functions as an agonist and sensitizes TRPV1-mediated $\mathrm{Ca}^{2+}$ increase. Although pain behavior in the second phase of the formalin pain model is significantly attenuated in BLT1-KO mice relative to WT mice, no analgesic effect has been observed in the first phase. This is because the first phase is mainly mediated by TRPA1 and TRPV1 gene expression, which do not change in the DRG and spinal cords of BLT1-KO mice. Hence, BLT1 may not be involved in mediating the properties of TRPA1 (McNamara et al., 2007; Asahara et al., 2015).

Resolvin D1 inhibits TRPA1, TRPV3, and TRPV4 in heterogeneous systems. FPR2/ALX is a resolvin D1 receptor, but treatment with FPR2/ALX agonists, cathelicidin LL-37 and Trp-Lys-Tyr-Met-Val-Met (WKYMVM), do not affect TRPA1, TPRV3, and TRPV4 inhibition (Bang et al., 2010). However, there is another resolvin D1 receptor, GPR32, that is also activated

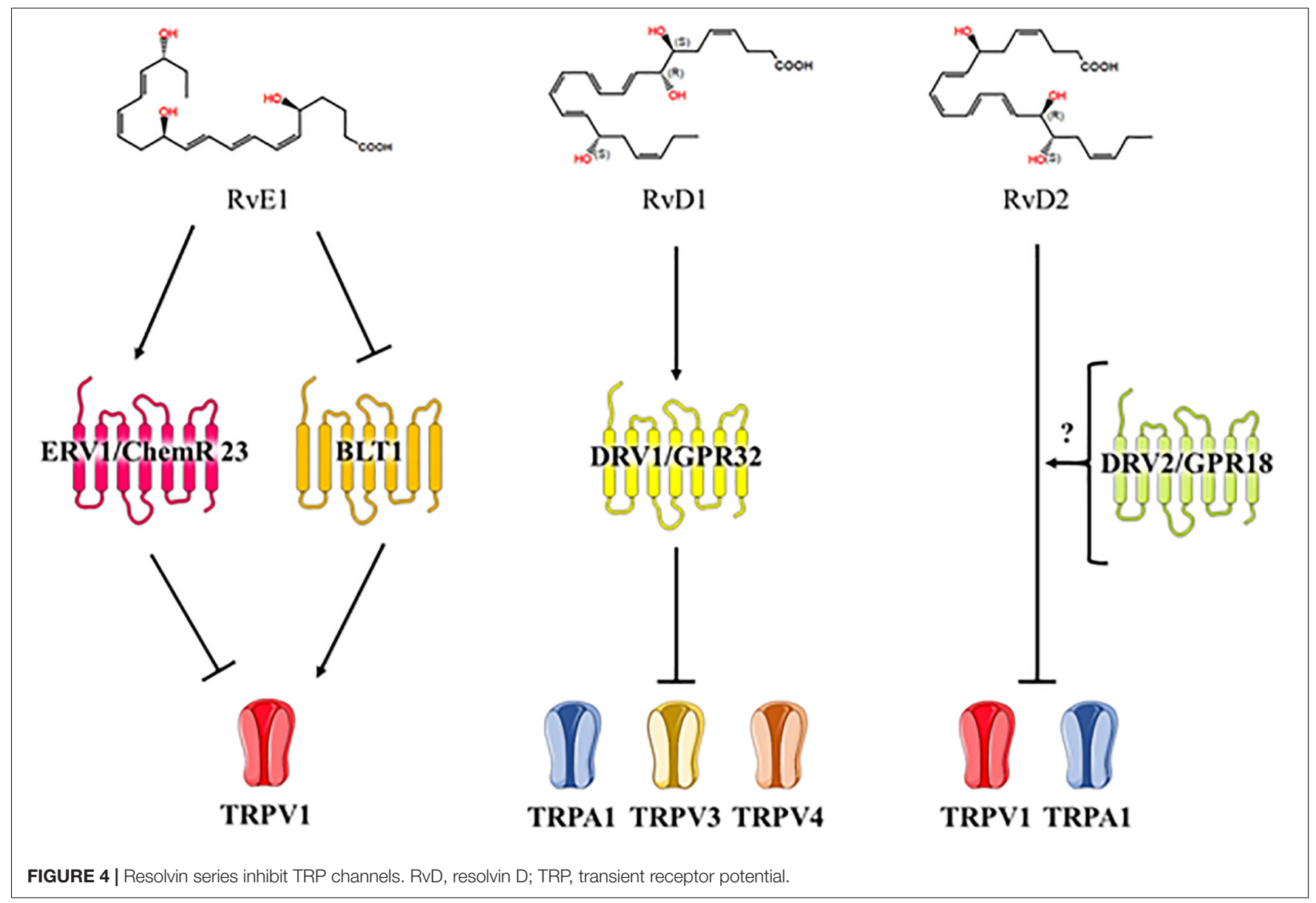


by AT-RvD1. FPR2/ALX and GPR32 are GPCRs that regulate specific microRNAs and their target genes that promote the resolution of acute inflammation (Krishnamoorthy et al., 2012).

Resolvin D2 is known to activate a cell surface GPCR, GPR18/DRV2 (Chiang et al., 2015, 2017). GPR18 is expressed in lumbar DRG and in the spinal cord at a genetic level and under neuropathic conditions; it is also upregulated in the spinal cord (Malek et al., 2016). Resolvin D2 inhibits TRPV1 and TRPA1 activation dose-dependently. Resolvin D2 is ten times more potent than resolvin $\mathrm{E} 1$ on TRPV1 inhibition $\left(\mathrm{IC}_{50}=0.04 \pm 0.01\right.$ and $0.4 \pm 0.05$, respectively), and it is four times more potent than resolvin D1 on TRPA1 inhibition $\left(\mathrm{IC}_{50}=0.8 \pm 0.2\right.$ and $3.2 \pm 0.05$, respectively) (Park et al., 2011b).

\section{RESOLVINS ALLEVIATE CHRONIC PAIN}

\section{Resolvins in the Resolution of Inflammatory Pain}

Studies have shown that both peripheral (intraplanar) and central (intrathecal) administration of RvE1 and RvD1 reduce inflammatory pain (Bang et al., 2010; Xu et al., 2010; LimaGarcia et al., 2011; Park et al., 2011b) and postoperative pain (Huang et al., 2011; Wang and Strichartz, 2017) by modulating the activation of TRP channels. Bang et al. reported that pretreatment with RvD1 (20 ng) suppressed pain behaviors induced by intraplanar formalin injection (Bang et al., 2010) and attempted to determine whether activators of the RvD1 receptor (FPR2/ALX) inhibits the effect of TRP channels (TRPV3/4 and A1), however, no such effect was found (Krishnamoorthy et al., 2010). Xu et al. (2010) found that both RvD1 and RvE1 (1$20 \mathrm{ng}$ ) suppressed inflammatory pain behaviors induced by formalin, carrageenan, or complete Freund's adjuvant (CFA); they also indicated that the possible mechanism where RvE1 inhibits ERK signaling pathways to block TNF- $\alpha$ induced increased EPSC frequency and NMDAR hyperactivity in spinal dorsal horn neurons. Additionally, an agonist of ChemR23, which was considered to be an RvE1 receptor, also abolished capsaicininduced increase in sEPSC frequency, implicating the role of RvE1 in mediating TRPV1 activity via ChemR23. Moreover, Park et al. examined RvD2 at very low doses (10 ng) injected intrathecally and found that it prevented spontaneous pain induced by formalin as well as reversed inflammatory pain induced by CFA (Park et al., 2011b). They identified RvD2 as endogenous inhibitors both for TRPV1 and TRPA1, by which RvD2 acts on specific GPCRs. Table 1 shows a list of the published findings of the resolution effect of resolvins specifically on TRP channels for inflammatory pain.

\section{Resolvins in the Resolution of Neuropathic Pain}

While there is mounting research on the analgesic effect of resolvins in inflammatory pain, the role of resolvins in TRP channels to alleviate neuropathic pain is not well known. One study evaluated the analgesic actions of resolvin D-series (D1 to D5) in a TRPA1 and TRPV1 knockout mouse model of chemotherapy-induced peripheral neuropathy induced by paclitaxel (Luo et al., 2019). They found that RvD1 and RvD2 reduced mechanical allodynia in both sexes of TRPV1 and TRPA1 deficient mice, whereas RvD3 and RvD4 had no effects on either sex. Interestingly, RvD5 reduced mechanical allodynia only in male mice but not in female mice, indicating there is a sex dimorphism in pain regulation. Since RvD5 affected the TRPV1 and TRPA1 knockout male mice only, this might implicate the TRP channel in the role of RvD5 to attenuate neuropathic pain in female mice.

TABLE 1 | Analgesic effects of different resolvins in distinctive TRP channels for inflammatory and neuropathic pain.

\begin{tabular}{|c|c|c|c|c|c|}
\hline Research article & Pain type & Resolvin & TRP channel & Results & Potential mechanisms \\
\hline Bang et al., 2010 & Inflammatory & RvD1 & $\begin{array}{l}\text { TRPA1 } \\
\text { TRPV3 } \\
\text { TRPV4 }\end{array}$ & $\begin{array}{l}\downarrow \text { activities the three TRP channels at } \\
\text { nanomolar and micromolar levels } \\
{ }^{*} \text { No effects of FPR } 2 / A L X \text { agonists on } \\
\text { the three TRP channels }\end{array}$ & \\
\hline Xu et al., 2010 & Inflammatory & $\begin{array}{l}\text { RvE1 } \\
\text { RvD1 }\end{array}$ & TRPV1 & $\begin{array}{l}\downarrow \text { EPSC frequency increases induced by } \\
\text { capsaicin, with the ChemR23 agonist } \\
\downarrow \text { EPSC frequency increase by TNF- } \alpha \\
\text { and NMDAR hyperactivity with RvE1 }\end{array}$ & $\begin{array}{l}\text { RvE1 modulates the ERK signaling } \\
\text { pathway to abolish TNF- } \alpha \text {-evoked } \\
\text { NMDA receptor hyperactivity in dorsal } \\
\text { horn neurons }\end{array}$ \\
\hline Park et al., 2011b & Inflammatory & $\begin{array}{l}\text { RvD1 } \\
\text { RvD2 } \\
\text { RvE1 }\end{array}$ & $\begin{array}{l}\text { TRPV1 } \\
\text { TRPA1 }\end{array}$ & 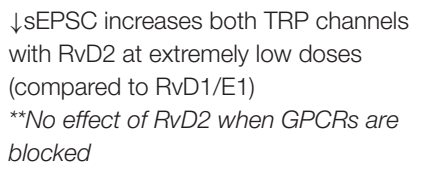 & $\begin{array}{l}\text { Distinct mechanisms of the resolvins in } \\
\text { regulating TRP channels } \\
\text { RVD2 involves specific GPCRs }\end{array}$ \\
\hline Luo et al., 2019 & $\begin{array}{l}\text { Neuropathic (CIPN } \\
\text { induced) } \\
\text { Inflammatory } \\
\left({ }^{\star \star} \text { RvD5 only }\right)\end{array}$ & $\begin{array}{l}\text { RvD1 } \\
\text { RvD2 } \\
\text { RvD5 }\end{array}$ & $\begin{array}{l}\text { TRPA1 } \\
\text { TRPV1 } \\
\left({ }^{* * K n o c k-o u t}\right. \\
\text { mice) }\end{array}$ & 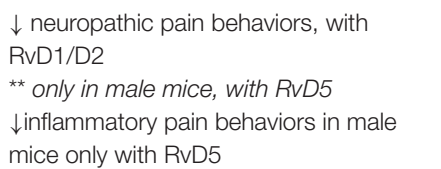 & $\begin{array}{l}\text { Sex dimorphism of RvD5's analgesia in } \\
\text { both pain models }\end{array}$ \\
\hline
\end{tabular}

CFA, complete Freund's adjuvant; CIPN, chemotherapy-induced peripheral neuropathy; EPSC, excitatory postsynaptic current; ERK, extracellular signal-regulated kinase;

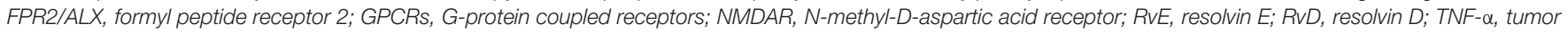
necrosis factor- $\alpha$; TRP, transient receptor potential. ** Indicates supplementary information. 


\section{CONCLUSION: IMPORTANCE OF PAIN RELIEF USING RESOLVINS VIA TRP MODULATION}

Opioid and non-opioid analgesic drugs for the treatment acute and chronic pain. Opioids are a type of medications that are used to relieve severe chronic pain. However, as opioid receptors are expressed throughout the entire nervous system and gastrointestinal tract and do not operate on specific pain pathways, their abuse and misuse can induce unexpected physiological and psychological side effects that devastate the lives of the affected individuals and their families. Morphine, one of the most widely prescribed opioid analgesics, increases pain hypersensitivity at low doses (Ghelardini et al., 2015). Morphine-6-glucuronide (M6G), a metabolite of morphine, has more potent analgesic effect than does morphine. However, M6G is dangerous to patients with renal failure and relate to respiratory depression (Lotsch, 2005). For these reasons, several nations and international organizations have thoroughly controlled the prescription and use of opioids (Rosenblum et al., 2008; Rogers et al., 2013). Further, the consequences of opioid use underscore the need to develop non-opioid analgesics and thus minimize the prescription of opioid analgesics.

Non-opioid analgesics include both selective and nonselective cyclooxygenase (COX) inhibitors, as well as well-known non-steroidal anti-inflammatory drugs and acetaminophen. COX contributes to the synthesis of PG, which causes inflammation, pain and fever. Because of this, COX inhibitors are used for antipyretics and antiphlogistics, as well as analgesics (Qureshi and Dua, 2020). However, the administration of COX-2 inhibitors can induce cardiovascular complications (Nussmeier et al., 2005).

Therefore, it is necessary to develop new analgesic targets that are specific to nociceptive neurons. One of the targets is TRP channels that mediate nociception, especially TRPV1. Many models have shown that TRPV1 inhibition reduces chronic pain

\section{REFERENCES}

Amir, R., and Devor, M. (2003). Electrical excitability of the soma of sensory neurons is required for spike invasion of the soma, but not for throughconduction. Biophys. J. 84, 2181-2191. doi: 10.1016/s0006-3495(03)75 024-3

Andersson, D. A., Gentry, C., Moss, S., and Bevan, S. (2008). Transient receptor potential A1 is a sensory receptor for multiple products of oxidative stress. J. Neurosci. 28, 2485-2494. doi: 10.1523/jneurosci.5369-07.2008

Andoh, T., and Kuraishi, Y. (2005). Expression of BLT1 leukotriene B4 receptor on the dorsal root ganglion neurons in mice. Brain Res. Mol. Brain Res 137, 263-266. doi: 10.1016/j.molbrainres.2005.02.029

Ariel, A., and Serhan, C. N. (2007). Resolvins and protectins in the termination program of acute inflammation. Trends Immunol. 28, 176-183. doi: 10.1016/j. it.2007.02.007

Asahara, M., Ito, N., Yokomizo, T., Nakamura, M., Shimizu, T., and Yamada, Y. (2015). The absence of the leukotriene B4 receptor BLT1 attenuates peripheral inflammation and spinal nociceptive processing following intraplantar formalin injury. Mol. Pain 11:11.

Bandell, M., Story, G. M., Hwang, S. W., Viswanath, V., Eid, S. R., Petrus, M. J., et al. (2004). Noxious cold ion channel TRPAl is activated by pungent compounds and bradykinin. Neuron 41, 849-857. doi: 10.1016/s0896-6273(04)00150-3 including inflammatory and neuropathic pain. TRP channels in nerve systems have been emerging targets for pain management, and several TRPV1 antagonists (ABT-102, AMG-517, AZD-1386, DWP-05195, JTS-653, MK-2295, PHE-377 and SB-705498) have already entered clinical trials (Wu et al., 2018). However, TRPV1 antagonists can induce abnormal changes in body temperature (hyperthermia and hypothermia (Gavva et al., 2008; Garami et al., 2018, 2020) or decrease heat sensation (Crutchlow et al., 2009). For these reasons, many TRPV1 antagonists have failed to be developed as painkillers.

Nevertheless, TRPV1 inhibitors are still being discovered. Resolvins, a class of lipid mediators, has been identified in this capacity. Resolvins are produced from omega-3 fatty acids and therefore have a great potential for reducing the incidence of side effects associated with pain management. Further, the fact that resolvins can attenuate powerful type cardiovascular disease enhances its potential as a useful analgesic (Salic et al., 2016; Capo et al., 2018). The analgesic role of resolvins has already been proven at nanomolar levels, resolvins are excellent potential therapeutic targets for pain. However, most current studies of resolvins in an analgesic role have been limited to inflammatory pain. Therefore, more studies on the analgesic effect of resolvins for neuropathic pain are needed.

\section{AUTHOR CONTRIBUTIONS}

$\mathrm{C}-\mathrm{KP}$ and YHK conceived and supervised the project. JR, EJG, J-WP, YHK, and C-KP wrote the manuscript. All authors contributed to the article and approved the submitted version.

\section{FUNDING}

This work was supported by the National Research Foundation of Korea (NRF-2017M3A9E4057929), which is funded by the Korean government.

Bang, S., Yoo, S., Yang, T. J., Cho, H., Kim, Y. G., and Hwang, S. W. (2010). Resolvin D1 attenuates activation of sensory transient receptor potential channels leading to multiple anti-nociception. Br. J. Pharmacol. 161, 707-720. doi: 10.1111/j.1476-5381.2010.00909.x

Baron, R. (2009). Neuropathic pain: a clinical perspective. Handb. Exp. Pharmacol. 2009, 3-30. doi: 10.1007/978-3-540-79090-7_1

Barton, N. J., Mcqueen, D. S., Thomson, D., Gauldie, S. D., Wilson, A. W., Salter, D. M., et al. (2006). Attenuation of experimental arthritis in TRPV1R knockout mice. Exp. Mol. Pathol. 81, 166-170. doi: 10.1016/j.yexmp.2006.04.007

Basbaum, A. I., Bautista, D. M., Scherrer, G., and Julius, D. (2009). Cellular and molecular mechanisms of pain. Cell 139, 267-284.

Bautista, D. M., Jordt, S. E., Nikai, T., Tsuruda, P. R., Read, A. J., Poblete, J., et al. (2006). TRPAl mediates the inflammatory actions of environmental irritants and proalgesic agents. Cell 124, 1269-1282. doi: 10.1016/j.cell.2006.02.023

Bautista, D. M., Movahed, P., Hinman, A., Axelsson, H. E., Sterner, O., Hogestatt, E. D., et al. (2005). Pungent products from garlic activate the sensory ion channel TRPA1. Proc. Natl. Acad. Sci. U.S.A. 102, 12248-12252. doi: 10.1073/ pnas.0505356102

Bishop, B. (1980). Pain: its physiology and rationale for management. Part II. Analgesic systems of the CNS. Phys. Ther. 60, 21-23. doi: 10.1093/ptj/60.1.21

Bolcskei, K., Helyes, Z., Szabo, A., Sandor, K., Elekes, K., Nemeth, J., et al. (2005). Investigation of the role of TRPV1 receptors in acute and chronic nociceptive 
processes using gene-deficient mice. Pain 117, 368-376. doi: 10.1016/j.pain. 2005.06.024

Capo, X., Martorell, M., Busquets-Cortes, C., Tejada, S., Tur, J. A., Pons, A., et al. (2018). Resolvins as proresolving inflammatory mediators in cardiovascular disease. Eur. J. Med. Chem. 153, 123-130. doi: 10.1016/j.ejmech.2017.07.018

Caterina, M. J. (2007). Transient receptor potential ion channels as participants in thermosensation and thermoregulation. Am. J. Physiol. Regul. Integr, Comp. Physiol. 292, R64-R76.

Caterina, M. J., Leffler, A., Malmberg, A. B., Martin, W. J., Trafton, J., PetersenZeitz, K. R., et al. (2000). Impaired nociception and pain sensation in mice lacking the capsaicin receptor. Science 288, 306-313. doi: 10.1126/science.288. 5464.306

Caterina, M. J., Schumacher, M. A., Tominaga, M., Rosen, T. A., Levine, J. D., and Julius, D. (1997). The capsaicin receptor: a heat-activated ion channel in the pain pathway. Nature 389, 816-824. doi: 10.1038/39807

Chen, J., Joshi, S. K., Didomenico, S., Perner, R. J., Mikusa, J. P., Gauvin, D. M., et al. (2011). Selective blockade of TRPA1 channel attenuates pathological pain without altering noxious cold sensation or body temperature regulation. Pain 152, 1165-1172. doi: 10.1016/j.pain.2011.01.049

Chiang, N., Dalli, J., Colas, R. A., and Serhan, C. N. (2015). Identification of resolvin D2 receptor mediating resolution of infections and organ protection. J. Exp. Med. 212, 1203-1217. doi: 10.1084/jem.20150225

Chiang, N., De La Rosa, X., Libreros, S., and Serhan, C. N. (2017). Novel resolvin D2 receptor axis in infectious inflammation. J. Immunol. 198, 842-851. doi: 10.4049/jimmunol.1601650

Chung, M. K., and Caterina, M. J. (2007). TRP channel knockout mice lose their cool. Neuron 54, 345-347. doi: 10.1016/j.neuron.2007.04.025

Clapham, D. E. (2003). TRP channels as cellular sensors. Nature 426, 517-524. doi: 10.1038/nature02196

Cosens, D. J., and Manning, A. (1969). Abnormal electroretinogram from a Drosophila mutant. Nature 224, 285-287. doi: 10.1038/224285a0

Crutchlow, M., Dong, Y., Schulz, V., Von Hoydonck, P., Laethem, T., and Maes, A. (2009). "Pharmacologic inhibition of TRPV1 impairs sensation of potentially injurious heat in healthy subjects. 2009," in ASCPT 2009 Annual Meeting, National Harbor, MD, 69.

Dai, Y. (2016). TRPs and pain. Semin. Immunopathol. 38, 277-291. doi: 10.1007/ s00281-015-0526-0

Dai, Y., Wang, S., Tominaga, M., Yamamoto, S., Fukuoka, T., Higashi, T., et al. (2007). Sensitization of TRPA1 by PAR2 contributes to the sensation of inflammatory pain. J. Clin. Invest. 117, 1979-1987. doi: 10.1172/jci30951

Dalli, J., Winkler, J. W., Colas, R. A., Arnardottir, H., Cheng, C. Y., Chiang, N., et al. (2013). Resolvin D3 and aspirin-triggered resolvin D3 are potent immunoresolvents. Chem. Biol. 20, 188-201. doi: 10.1016/j.chembiol.2012.11.010

Davis, J. B., Gray, J., Gunthorpe, M. J., Hatcher, J. P., Davey, P. T., Overend, P., et al. (2000). Vanilloid receptor-1 is essential for inflammatory thermal hyperalgesia. Nature 405, 183-187.

Fernyhough, P., and Calcutt, N. A. (2010). Abnormal calcium homeostasis in peripheral neuropathies. Cell Calcium 47, 130-139. doi: 10.1016/j.ceca.2009. 11.008

Flower, R. J., and Perretti, M. (2005). Controlling inflammation: a fat chance? J. Exp. Med. 201, 671-674.

Francos-Quijorna, I., Santos-Nogueira, E., Gronert, K., Sullivan, A. B., Kopp, M. A., Brommer, B., et al. (2017). Maresin 1 promotes inflammatory resolution, neuroprotection, and functional neurological recovery after spinal cord injury. J. Neurosci. 37, 11731-11743. doi: 10.1523/jneurosci.1395-17.2017

Freire, M. O., and Van Dyke, T. E. (2013). Natural resolution of inflammation. Periodontol 2000, 149-164. doi: 10.1111/prd.12034

Fukuoka, T., Kondo, E., Dai, Y., Hashimoto, N., and Noguchi, K. (2001). Brainderived neurotrophic factor increases in the uninjured dorsal root ganglion neurons in selective spinal nerve ligation model. J. Neurosci. 21, 4891-4900. doi: 10.1523/jneurosci.21-13-04891.2001

Furue, H., Katafuchi, T., and Yoshimura, M. (2004). Sensory processing and functional reorganization of sensory transmission under pathological conditions in the spinal dorsal horn. Neurosci. Res. 48, 361-368. doi: 10.1016/j. neures.2003.12.005

Garami, A., Pakai, E., Mcdonald, H. A., Reilly, R. M., Gomtsyan, A., Corrigan, J. J., et al. (2018). TRPV1 antagonists that cause hypothermia, instead of hyperthermia, in rodents: compounds' pharmacological profiles, in vivo targets, thermoeffectors recruited and implications for drug development. Acta Physiol. 223:e13038. doi: 10.1111/apha. 13038

Garami, A., Shimansky, Y. P., Rumbus, Z., Vizin, R. C. L., Farkas, N., Hegyi, J., et al. (2020). Hyperthermia induced by transient receptor potential vanilloid1 (TRPV1) antagonists in human clinical trials: insights from mathematical modeling and meta-analysis. Pharmacol. Ther. 208:107474. doi: 10.1016/j. pharmthera.2020.107474

Gavva, N. R., Treanor, J. J., Garami, A., Fang, L., Surapaneni, S., Akrami, A., et al. (2008). Pharmacological blockade of the vanilloid receptor TRPV1 elicits marked hyperthermia in humans. Pain 136, 202-210. doi: 10.1016/j.pain.2008. 01.024

Ghelardini, C., Di Cesare Mannelli, L., and Bianchi, E. (2015). The pharmacological basis of opioids. Clin. Cases Miner Bone Metab. 12, 219-221.

Gibson, D. A., and Ma, L. (2011). Developmental regulation of axon branching in the vertebrate nervous system. Development 138, 183-195. doi: 10.1242/dev. 046441

Gleissman, H., Yang, R., Martinod, K., Lindskog, M., Serhan, C. N., Johnsen, J. I., et al. (2010). Docosahexaenoic acid metabolome in neural tumors: identification of cytotoxic intermediates. Faseb J. 24, 906-915. doi: 10.1096/ fj.09- 137919

Gong, T., Liu, L., Jiang, W., and Zhou, R. (2020). DAMP-sensing receptors in sterile inflammation and inflammatory diseases. Nat. Rev. Immunol. 20, 95-112. doi: 10.1038/s41577-019-0215-7

Guo, J., Wang, C., Niu, X., Zhou, F., Li, H., and Gao, W. (2019). Effects of resveratrol in the signaling of neuropathic pain involving P2X3 in the dorsal root ganglion of rats. Acta Neurol. Belg. 1-8.

Hara, T., Chiba, T., Abe, K., Makabe, A., Ikeno, S., Kawakami, K., et al. (2013). Effect of paclitaxel on transient receptor potential vanilloid 1 in rat dorsal root ganglion. Pain 154, 882-889. doi: 10.1016/j.pain.2013.02.023

Hasegawa, H., Abbott, S., Han, B. X., Qi, Y., and Wang, F. (2007). Analyzing somatosensory axon projections with the sensory neuron-specific Advillin gene. J. Neurosci. 27, 14404-14414. doi: 10.1523/jneurosci.4908-07. 2007

Herova, M., Schmid, M., Gemperle, C., and Hersberger, M. (2015). ChemR23, the receptor for chemerin and resolvin $\mathrm{E} 1$, is expressed and functional on M1 but not on M2 macrophages. J. Immunol. 194, 2330-2337. doi: 10.4049/jimmunol. 1402166

Hinman, A., Chuang, H. H., Bautista, D. M., and Julius, D. (2006). TRP channel activation by reversible covalent modification. Proc. Natl. Acad. Sci. U.S.A. 103, 19564-19568. doi: 10.1073/pnas.0609598103

Huang, L., Wang, C. F., Serhan, C. N., and Strichartz, G. (2011). Enduring prevention and transient reduction of postoperative pain by intrathecal resolvin D1. Pain 152, 557-565. doi: 10.1016/j.pain.2010.11.021

Hucho, T., and Levine, J. D. (2007). Signaling pathways in sensitization: toward a nociceptor cell biology. Neuron 55, 365-376. doi: 10.1016/j.neuron.2007. 07.008

Hudson, L. J., Bevan, S., Wotherspoon, G., Gentry, C., Fox, A., and Winter, J. (2001). VR1 protein expression increases in undamaged DRG neurons after partial nerve injury. Eur. J. Neurosci. 13, 2105-2114. doi: 10.1046/j.0953-816x. 2001.01591.x

Hylden, J. L., Nahin, R. L., Traub, R. J., and Dubner, R. (1989). Expansion of receptive fields of spinal lamina $\mathrm{I}$ projection neurons in rats with unilateral adjuvant-induced inflammation: the contribution of dorsal horn mechanisms. Pain 37, 229-243. doi: 10.1016/0304-3959(89)90135-8

Isobe, Y., Arita, M., Matsueda, S., Iwamoto, R., Fujihara, T., Nakanishi, H., et al. (2012). Identification and structure determination of novel anti-inflammatory mediator resolvin E3, 17,18-dihydroxyeicosapentaenoic acid. J. Biol. Chem. 287, 10525-10534. doi: 10.1074/jbc.m112.340612

Jang, Y., Kim, M., and Hwang, S. W. (2020). Molecular mechanisms underlying the actions of arachidonic acid-derived prostaglandins on peripheral nociception. J. Neuroinflammation 17:30.

Jardin, I., Lopez, J. J., Diez, R., Sanchez-Collado, J., Cantonero, C., Albarran, L., et al. (2017). TRPs in pain sensation. Front. Physiol. 8:392. doi: 10.3389/fphys. 2017.00392

Ji, R. R., Baba, H., Brenner, G. J., and Woolf, C. J. (1999). Nociceptive-specific activation of ERK in spinal neurons contributes to pain hypersensitivity. Nat. Neurosci. 2, 1114-1119. doi: 10.1038/16040 
Ji, R. R., Nackley, A., Huh, Y., Terrando, N., and Maixner, W. (2018). Neuroinflammation and central sensitization in chronic and widespread pain. Anesthesiology 129, 343-366. doi: 10.1097/aln.0000000000002130

Ji, R. R., Samad, T. A., Jin, S. X., Schmoll, R., and Woolf, C. J. (2002). p38 MAPK activation by NGF in primary sensory neurons after inflammation increases TRPV1 levels and maintains heat hyperalgesia. Neuron 36, 57-68. doi: 10.1016/ s0896-6273(02)00908-x

Ji, R. R., and Suter, M. R. (2007). p38 MAPK, microglial signaling, and neuropathic pain. Mol. Pain 3:33.

Ji, R. R., and Woolf, C. J. (2001). Neuronal plasticity and signal transduction in nociceptive neurons: implications for the initiation and maintenance of pathological pain. Neurobiol. Dis. 8, 1-10. doi: 10.1006/nbdi.2000.0360

Ji, R. R., Xu, Z. Z., Strichartz, G., and Serhan, C. N. (2011). Emerging roles of resolvins in the resolution of inflammation and pain. Trends Neurosci. 34, 599-609. doi: 10.1016/j.tins.2011.08.005

Jo, Y. Y., Lee, J. Y., and Park, C. K. (2016). Resolvin E1 inhibits substance P-Induced potentiation of TRPV1 in primary sensory neurons. Mediators Inflamm. 2016:5259321.

Jordt, S. E., Bautista, D. M., Chuang, H. H., Mckemy, D. D., Zygmunt, P. M., Hogestatt, E. D., et al. (2004). Mustard oils and cannabinoids excite sensory nerve fibres through the TRP channel ANKTM1. Nature 427, 260-265. doi: 10.1038/nature 02282

Julius, D., and Basbaum, A. I. (2001). Molecular mechanisms of nociception. Nature 413, 203-210. doi: 10.1038/35093019

Jung, H., Toth, P. T., White, F. A., and Miller, R. J. (2008). Monocyte chemoattractant protein- 1 functions as a neuromodulator in dorsal root ganglia neurons. J. Neurochem. 104, 254-263.

Kanai, Y., Nakazato, E., Fujiuchi, A., Hara, T., and Imai, A. (2005). Involvement of an increased spinal TRPV1 sensitization through its up-regulation in mechanical allodynia of CCI rats. Neuropharmacology 49, 977-984. doi: 10. 1016/j.neuropharm.2005.05.003

Kanda, H., Kobayashi, K., Yamanaka, H., and Noguchi, K. (2013). COX-1dependent prostaglandin D2 in microglia contributes to neuropathic pain via DP2 receptor in spinal neurons. Glia 61, 943-956. doi: 10.1002/glia.22487

Karashima, Y., Talavera, K., Everaerts, W., Janssens, A., Kwan, K. Y., Vennekens, R., et al. (2009). TRPA1 acts as a cold sensor in vitro and in vivo. Proc. Natl. Acad. Sci. U.S.A. 106, 1273-1278. doi: 10.1073/pnas.0808487106

Keeble, J., Russell, F., Curtis, B., Starr, A., Pinter, E., and Brain, S. D. (2005). Involvement of transient receptor potential vanilloid 1 in the vascular and hyperalgesic components of joint inflammation. Arthritis Rheum 52, 32483256. doi: 10.1002/art.21297

Krishnamoorthy, S., Recchiuti, A., Chiang, N., Fredman, G., and Serhan, C. N. (2012). Resolvin D1 receptor stereoselectivity and regulation of inflammation and proresolving microRNAs. Am. J. Pathol. 180, 2018-2027. doi: 10.1016/j. ajpath.2012.01.028

Krishnamoorthy, S., Recchiuti, A., Chiang, N., Yacoubian, S., Lee, C. H., Yang, R., et al. (2010). Resolvin D1 binds human phagocytes with evidence for proresolving receptors. Proc. Natl. Acad. Sci. U.S.A. 107, 1660-1665. doi: 10. 1073/pnas.0907342107

Lappin, S. C., Randall, A. D., Gunthorpe, M. J., and Morisset, V. (2006). TRPV1 antagonist, SB-366791, inhibits glutamatergic synaptic transmission in rat spinal dorsal horn following peripheral inflammation. Eur. J. Pharmacol. 540, 73-81. doi: 10.1016/j.ejphar.2006.04.046

Latremoliere, A., and Woolf, C. J. (2009). Central sensitization: a generator of pain hypersensitivity by central neural plasticity. J. Pain 10, 895-926. doi: 10.1016/j.jpain.2009.06.012

Lee, H. N., Kundu, J. K., Cha, Y. N., and Surh, Y. J. (2013). Resolvin D1 stimulates efferocytosis through $\mathrm{p} 50 / \mathrm{p} 50$-mediated suppression of tumor necrosis factoralpha expression. J. Cell Sci. 126, 4037-4047. doi: 10.1242/jcs.131003

Lee, S. E., and Kim, J. H. (2007). Involvement of substance P and calcitonin generelated peptide in development and maintenance of neuropathic pain from spinal nerve injury model of rat. Neurosci. Res. 58, 245-249. doi: 10.1016/j. neures.2007.03.004

Levy, B. D., Clish, C. B., Schmidt, B., Gronert, K., and Serhan, C. N. (2001). Lipid mediator class switching during acute inflammation: signals in resolution. Nat. Immunol. 2, 612-619. doi: 10.1038/89759

Lim, J. Y., Park, C. K., and Hwang, S. W. (2015). Biological roles of resolvins and related substances in the resolution of pain. Biomed. Res. Int. 2015:830930.
Lima-Garcia, J. F., Dutra, R. C., Da Silva, K., Motta, E. M., Campos, M. M., and Calixto, J. B. (2011). The precursor of resolvin D series and aspirin-triggered resolvin D1 display anti-hyperalgesic properties in adjuvant-induced arthritis in rats. Br. J. Pharmacol. 164, 278-293. doi: 10.1111/j.1476-5381.2011.01345.x

Liu, L., Ji, F., Liang, J., He, H., Fu, Y., and Cao, M. (2012). Inhibition by dexmedetomidine of the activation of spinal dorsal horn glias and the intracellular ERK signaling pathway induced by nerve injury. Brain Res. 1427, 1-9. doi: 10.1016/j.brainres.2011.08.019

Lotsch, J. (2005). Opioid metabolites. J/ Pain Symptom. Manag. 29, S10-S24.

Luo, X., Gu, Y., Tao, X., Serhan, C. N., and Ji, R. R. (2019). Resolvin D5 inhibits neuropathic and inflammatory pain in male but not female mice: distinct actions of D-Series resolvins in chemotherapy-induced peripheral neuropathy. Front. Pharmacol. 10:745. doi: 10.3389/fphar.2019.00745

Macpherson, L. J., Geierstanger, B. H., Viswanath, V., Bandell, M., Eid, S. R., Hwang, S., et al. (2005). The pungency of garlic: activation of TRPA1 and TRPV1 in response to allicin. Curr. Biol. 15, 929-934. doi: 10.1016/j.cub.2005. 04.018

Macpherson, L. J., Xiao, B., Kwan, K. Y., Petrus, M. J., Dubin, A. E., Hwang, S., et al. (2007). An ion channel essential for sensing chemical damage. J. Neurosci. 27, 11412-11415. doi: 10.1523/jneurosci.3600-07.2007

Malek, N., Kostrzewa, M., Makuch, W., Pajak, A., Kucharczyk, M., Piscitelli, F., et al. (2016). The multiplicity of spinal AA-5-HT anti-nociceptive action in a rat model of neuropathic pain. Pharmacol. Res. 111, 251-263. doi: 10.1016/j. phrs.2016.06.012

Martini, A. C., Berta, T., Forner, S., Chen, G., Bento, A. F., Ji, R. R., et al. (2016). Lipoxin A4 inhibits microglial activation and reduces neuroinflammation and neuropathic pain after spinal cord hemisection. J. Neuroinflammation 13:75.

McDonald, B., and Kubes, P. (2010). Chemokines: sirens of neutrophil recruitment-but is it just one song? Immunity 33, 148-149. doi: 10.1016/j. immuni.2010.08.006

McNamara, C. R., Mandel-Brehm, J., Bautista, D. M., Siemens, J., Deranian, K. L., Zhao, M., et al. (2007). TRPA1 mediates formalin-induced pain. Proc. Natl. Acad. Sci. U.S.A. 104, 13525-13530. doi: 10.1073/pnas.0705924104

Melzack, R., and Wall, P. D. (1962). On the nature of cutaneous sensory mechanisms. Brain 85, 331-356. doi: 10.1093/brain/85.2.331

Metzemaekers, M., Gouwy, M., and Proost, P. (2020). Neutrophil chemoattractant receptors in health and disease: double-edged swords. Cell Mol. Immunol. 17, 433-450. doi: 10.1038/s41423-020-0412-0

Michael, G. J., and Priestley, J. V. (1999). Differential expression of the mRNA for the vanilloid receptor subtype 1 in cells of the adult rat dorsal root and nodose ganglia and its downregulation by axotomy. J. Neurosci. 19, 1844-1854. doi: 10.1523/jneurosci.19-05-01844.1999

Morenilla-Palao, C., Planells-Cases, R., Garcia-Sanz, N., and Ferrer-Montiel, A. (2004). Regulated exocytosis contributes to protein kinase C potentiation of vanilloid receptor activity. J. Biol. Chem. 279, 25665-25672. doi: 10.1074/jbc. m311515200

Mourot, A., Herold, C., Kienzler, M. A., and Kramer, R. H. (2018). Understanding and improving photo-control of ion channels in nociceptors with azobenzene photo-switches. Br. J. Pharmacol. 175, 2296-2311. doi: 10.1111/bph.13923

Nagi, S. S., Marshall, A. G., Makdani, A., Jarocka, E., Liljencrantz, J., Ridderstrom, M., et al. (2019). An ultrafast system for signaling mechanical pain in human skin. Sci. Adv. 5:eaaw1297. doi: 10.1126/sciadv.aaw1297

Nakayama, Y., Omote, K., and Namiki, A. (2002). Role of prostaglandin receptor EP1 in the spinal dorsal horn in carrageenan-induced inflammatory pain. Anesthesiology 97, 1254-1262. doi: 10.1097/00000542-200211000-00032

Nassini, R., Gees, M., Harrison, S., De Siena, G., Materazzi, S., Moretto, N., et al. (2011). Oxaliplatin elicits mechanical and cold allodynia in rodents via TRPA1 receptor stimulation. Pain 152, 1621-1631. doi: 10.1016/j.pain.2011. 02.051

Nguyen, N. L., Van Buren, V., Reimert, R., and Von Garnier, A. (2005). Determination of porosity and flow distribution in packed beds by magnetic resonance imaging. Magn. Reson. Imaging 23, 395-396. doi: 10.1016/j.mri.2004. 11.061

Noguchi, K., and Okubo, M. (2011). Leukotrienes in nociceptive pathway and neuropathic/inflammatory pain. Biol. Pharm. Bull. 34, 1163-1169. doi: 10.1248/ bpb.34.1163

Nussmeier, N. A., Whelton, A. A., Brown, M. T., Langford, R. M., Hoeft, A., Parlow, J. L., et al. (2005). Complications of the COX-2 inhibitors parecoxib 
and valdecoxib after cardiac surgery. N. Engl. J. Med. 352, 1081-1091. doi: 10.1056/nejmoa050330

Obata, K., Katsura, H., Mizushima, T., Yamanaka, H., Kobayashi, K., Dai, Y., et al. (2005). TRPA1 induced in sensory neurons contributes to cold hyperalgesia after inflammation and nerve injury. J. Clin. Invest. 115, 2393-2401. doi: $10.1172 /$ jci25437

Okubo, M., Yamanaka, H., Kobayashi, K., and Noguchi, K. (2010). Leukotriene synthases and the receptors induced by peripheral nerve injury in the spinal cord contribute to the generation of neuropathic pain. Glia 58, 599-610.

Pace, M. C., Passavanti, M. B., De Nardis, L., Bosco, F., Sansone, P., Pota, V., et al. (2018). Nociceptor plasticity: a closer look. J. Cell Physiol. 233, 2824-2838. doi: $10.1002 /$ jcp. 25993

Park, C. K., Lu, N., Xu, Z. Z., Liu, T., Serhan, C. N., and Ji, R. R. (2011a), Resolving TRPV1- and TNF-alpha-mediated spinal cord synaptic plasticity and inflammatory pain with neuroprotectin D1. J. Neurosci. 31, 15072-15085. doi: 10.1523/jneurosci.2443-11.2011

Park, C. K., Xu, Z. Z., Liu, T., Lu, N., Serhan, C. N., and Ji, R. R. (2011b). Resolvin D2 is a potent endogenous inhibitor for transient receptor potential subtype V1/A1, inflammatory pain, and spinal cord synaptic plasticity in mice: distinct roles of resolvin D1. D2, and E1. J. Neurosci. 31, 18433-18438. doi: 10.1523/ jneurosci.4192-11.2011

Patapoutian, A., Tate, S., and Woolf, C. J. (2009). Transient receptor potential channels: targeting pain at the source. Nat. Rev. Drug Discov. 8, 55-68. doi: $10.1038 / \mathrm{nrd} 2757$

Peiseler, M., and Kubes, P. (2019). More friend than foe: the emerging role of neutrophils in tissue repair. J. Clin. Invest. 129, 2629-2639. doi: 10.1172/ jci124616

Pirault, J., and Back, M. (2018). Lipoxin and resolvin receptors transducing the resolution of inflammation in cardiovascular disease. Front. Pharmacol. 9:1273. doi: $10.3389 /$ fphar.2018.01273

Qureshi, O., and Dua, A. (2020). COX Inhibitors. Treasure Island, FL: StatPearls.

Raja, S. N., Carr, D. B., Cohen, M., Finnerup, N. B., Flor, H., Gibson, S., et al. (2020), The revised international association for the study of pain definition of pain: concepts, challenges, and compromises. Pain 161, 1976-1982.

Ramsey, I. S., Delling, M., and Clapham, D. E. (2006). An introduction to TRP channels. Annu. Rev. Physiol. 68, 619-647.

Rogers, E., Mehta, S., Shengelia, R., and Reid, M. C. (2013). Four strategies for managing opioid-induced side effects in older adults. Clin. Geriatr. 21, 1-14.

Rosenblum, A., Marsch, L. A., Joseph, H., and Portenoy, R. K. (2008). Opioids and the treatment of chronic pain: controversies, current status, and future directions. Exp. Clin. Psychopharmacol. 16, 405-416. doi: 10.1037/a0013628

Rymut, N., Heinz, J., Sadhu, S., Hosseini, Z., Riley, C. O., Marinello, M., et al. (2020). Resolvin D1 promotes efferocytosis in aging by limiting senescent cell-induced MerTK cleavage. FASEB J. 34, 597-609. doi: 10.1096/fj.201902126r

Salas, M. M., Hargreaves, K. M., and Akopian, A. N. (2009). TRPA1-mediated responses in trigeminal sensory neurons: interaction between TRPA1 and TRPV1. Eur. J. Neurosci. 29, 1568-1578. doi: 10.1111/j.1460-9568.2009.06702.x

Salic, K., Morrison, M. C., Verschuren, L., Wielinga, P. Y., Wu, L., Kleemann, R., et al. (2016). Resolvin E1 attenuates atherosclerosis in absence of cholesterollowering effects and on top of atorvastatin. Atherosclerosis 250, 158-165. doi: 10.1016/j.atherosclerosis.2016.05.001

Sawada, Y., Hosokawa, H., Matsumura, K., and Kobayashi, S. (2008). Activation of transient receptor potential ankyrin 1 by hydrogen peroxide. Eur. J. Neurosci. 27, 1131-1142. doi: 10.1111/j.1460-9568.2008.06093.x

Scholz, J., and Woolf, C. J. (2002). Can we conquer pain? Nat. Neurosci. 5(Suppl.), 1062-1067. doi: $10.1038 / \mathrm{nn} 942$

Selders, G. S., Fetz, A. E., Radic, M. Z., and Bowlin, G. L. (2017). An overview of the role of neutrophils in innate immunity, inflammation and host-biomaterial integration. Regen. Biomater. 4, 55-68. doi: 10.1093/rb/rbw041

Seltzer, Z., Dubner, R., and Shir, Y. (1990). A novel behavioral model of neuropathic pain disorders produced in rats by partial sciatic nerve injury. Pain 43, 205-218. doi: 10.1016/0304-3959(90)91074-s

Serhan, C. N. (2007). Resolution phase of inflammation: novel endogenous antiinflammatory and proresolving lipid mediators and pathways. Annu. Rev. Immunol. 25, 101-137. doi: 10.1146/annurev.immunol.25.022106.141647

Serhan, C. N. (2014). Pro-resolving lipid mediators are leads for resolution physiology. Nature 510, 92-101. doi: 10.1038/nature13479
Serhan, C. N., and Chiang, N. (2013). Resolution phase lipid mediators of inflammation: agonists of resolution. Curr. Opin. Pharmacol. 13, 632-640. doi: 10.1016/j.coph.2013.05.012

Serhan, C. N., Chiang, N., Dalli, J., and Levy, B. D. (2015a). Lipid mediators in the resolution of inflammation. Cold Spring Harbor Perspect. Biol. 7:a016311.

Serhan, C. N., Chiang, N., and Dalli, J. (2015b). The resolution code of acute inflammation: novel pro-resolving lipid mediators in resolution. Semin. Immunol. 27, 200-215. doi: 10.1016/j.smim.2015.03.004

Serhan, C. N., Hong, S., Gronert, K., Colgan, S. P., Devchand, P. R., Mirick, G., et al. (2002). Resolvins: a family of bioactive products of omega-3 fatty acid transformation circuits initiated by aspirin treatment that counter proinflammation signals. J. Exp. Med. 196, 1025-1037.

Serhan, C. N., and Levy, B. D. (2018). Resolvins in inflammation: emergence of the pro-resolving superfamily of mediators. J. Clin. Invest. 128, 2657-2669. doi: $10.1172 /$ jci97943

Sexton, J. E., Vernon, J., and Wood, J. N. (2014). TRPs and pain. Handb. Exp. Pharmacol. 223, 873-897. doi: 10.1007/978-3-319-05161-1_6

Siemens, J., Zhou, S., Piskorowski, R., Nikai, T., Lumpkin, E. A., Basbaum, A. I., et al. (2006). Spider toxins activate the capsaicin receptor to produce inflammatory pain. Nature 444, 208-212. doi: 10.1038/nature05285

Song, X. S., Cao, J. L., Xu, Y. B., He, J. H., Zhang, L. C., and Zeng, Y. M. (2005). Activation of ERK/CREB pathway in spinal cord contributes to chronic constrictive injury-induced neuropathic pain in rats. Acta Pharmacol. Sin. 26, 789-798. doi: 10.1111/j.1745-7254.2005.00123.x

Spicarova, D., Nerandzic, V., and Palecek, J. (2011). Modulation of spinal cord synaptic activity by tumor necrosis factor alpha in a model of peripheral neuropathy. J. Neuroinflammation 8:177. doi: 10.1186/1742-20948-177

Stark, A. H., Crawford, M. A., and Reifen, R. (2008). Update on alpha-linolenic acid. Nutr. Rev. 66, 326-332. doi: 10.1111/j.1753-4887.2008.00040.x

Staruschenko, A., Jeske, N. A., and Akopian, A. N. (2010). Contribution of TRPV1TRPA1 interaction to the single channel properties of the TRPA1 channel. J. Biol. Chem. 285, 15167-15177. doi: 10.1074/jbc.m110.106153

Story, G. M., Peier, A. M., Reeve, A. J., Eid, S. R., Mosbacher, J., Hricik, T. R., et al. (2003). ANKTM1, a TRP-like channel expressed in nociceptive neurons, is activated by cold temperatures. Cell 112, 819-829. doi: 10.1016/s0092-8674(03) 00158-2

Suo, Z. W., Fan, Q. Q., Yang, X., and Hu, X. D. (2013). Ca2+ /calmodulindependent protein kinase II in spinal dorsal horn contributes to the pain hypersensitivity induced by gamma-aminobutyric acid type a receptor inhibition. J. Neurosci. Res. 91, 1473-1482. doi: 10.1002/jnr.23270

Tashima, R., Koga, K., Sekine, M., Kanehisa, K., Kohro, Y., Tominaga, K., et al. (2018). Optogenetic activation of non-nociceptive abeta fibers induces neuropathic pain-like sensory and emotional behaviors after nerve injury in rats. eNeuro 5:ENEURO.0450-17.2018. doi: 10.1523/ENEURO.0450-17. 2018

Tsuda, M., Shigemoto-Mogami, Y., Koizumi, S., Mizokoshi, A., Kohsaka, S., Salter, M. W., et al. (2003). P2X4 receptors induced in spinal microglia gate tactile allodynia after nerve injury. Nature 424, 778-783. doi: 10.1038/nature01786

Ulmann, L., Hatcher, J. P., Hughes, J. P., Chaumont, S., Green, P. J., Conquet, F., et al. (2008). Up-regulation of $\mathrm{P} 2 \mathrm{X} 4$ receptors in spinal microglia after peripheral nerve injury mediates BDNF release and neuropathic pain. J. Neurosci. 28, 11263-11268. doi: 10.1523/jneurosci.2308-08.2008

Veldhuis, N. A., Poole, D. P., Grace, M., Mcintyre, P., and Bunnett, N. W. (2015). The G protein-coupled receptor-transient receptor potential channel axis: molecular insights for targeting disorders of sensation and inflammation. Pharmacol. Rev. 67, 36-73. doi: 10.1124/pr.114.009555

Verkhratsky, A., and Fernyhough, P. (2008). Mitochondrial malfunction and $\mathrm{Ca} 2+$ dyshomeostasis drive neuronal pathology in diabetes. Cell Calcium. 44, 112-122. doi: $10.1016 / j . c e c a .2007 .11 .010$

Vilceanu, D., Honore, P., Hogan, Q. H., and Stucky, C. L. (2010). Spinal nerve ligation in mouse upregulates TRPV1 heat function in injured IB4-positive nociceptors. J. Pain 11, 588-599. doi: 10.1016/j.jpain.2009.09.018

Vriens, J., Watanabe, H., Janssens, A., Droogmans, G., Voets, T., and Nilius, B. (2004). Cell swelling, heat, and chemical agonists use distinct pathways for the activation of the cation channel TRPV4. Proc. Natl. Acad. Sci. U.S.A. 101, 396-401. doi: 10.1073/pnas.0303329101 
Wang, J. C., and Strichartz, G. R. (2017). Prevention of chronic post-thoracotomy pain in rats by intrathecal resolvin D1 and D2: effectiveness of perioperative and delayed drug delivery. J. Pain 18, 535-545. doi: 10.1016/j.jpain.2016.12.012

Wang, Z., Ling, D., Wu, C., Han, J., and Zhao, Y. (2020). Baicalin prevents the up-regulation of TRPV1 in dorsal root ganglion and attenuates chronic neuropathic pain. Vet. Med. Sci. 1-7.

Woodbury, C. J., Zwick, M., Wang, S., Lawson, J. J., Caterina, M. J., Koltzenburg, M., et al. (2004). Nociceptors lacking TRPV1 and TRPV2 have normal heat responses. J. Neurosci. 24, 6410-6415. doi: 10.1523/jneurosci.1421-04.2004

Woolf, C. J. (2010). What is this thing called pain? J. Clin. Invest. 120, 3742-3744.

Woolf, C. J. (2011). Central sensitization: implications for the diagnosis and treatment of pain. Pain 152, S2-S15.

Woolf, C. J., Shortland, P., and Coggeshall, R. E. (1992). Peripheral nerve injury triggers central sprouting of myelinated afferents. Nature 355, 75-78. doi: $10.1038 / 355075 \mathrm{a} 0$

Wu, Y., Heymann, H. M., and Gross, E. R. (2018). Non-opioid analgesic use and concerns for impaired organ protection. Br. J. Anaesth 120, 403-405. doi: 10.1016/j.bja.2017.11.070

Xu, X., Chen, H., Ling, B. Y., Xu, L., Cao, H., and Zhang, Y. Q. (2014). Extracellular signal-regulated protein kinase activation in spinal cord contributes to pain hypersensitivity in a mouse model of type 2 diabetes. Neurosci. Bull. 30, 53-66. doi: 10.1007/s12264-013-1387-y

Xu, Z. Z., Berta, T., and Ji, R. R. (2013). Resolvin E1 inhibits neuropathic pain and spinal cord microglial activation following peripheral nerve injury. J. Neuroimmune Pharmacol. 8, 37-41. doi: 10.1007/s11481-012-9394-8

Xu, Z. Z., Kim, Y. H., Bang, S., Zhang, Y., Berta, T., Wang, F., et al. (2015). Inhibition of mechanical allodynia in neuropathic pain by TLR5-mediated A-fiber blockade. Nat. Med. 21, 1326-1331. doi: 10.1038/nm.3978
Xu, Z. Z., Zhang, L., Liu, T., Park, J. Y., Berta, T., Yang, R., et al. (2010). Resolvins RvE1 and RvD1 attenuate inflammatory pain via central and peripheral actions. Nat. Med. 16, 592-597. doi: 10.1038/nm.2123

Yurdagul, A. Jr., Doran, A. C., Cai, B., Fredman, G., and Tabas, I. A. (2017). Mechanisms and consequences of defective efferocytosis in atherosclerosis. Front. Cardiovasc. Med. 4:86. doi: 10.3389/fcrm.2017.00086

Zhang, X., Huang, J., and Mcnaughton, P. A. (2005). NGF rapidly increases membrane expression of TRPV1 heat-gated ion channels. EMBO J. 24, 42114223. doi: 10.1038/sj.emboj.7600893

Zhao, M., Isami, K., Nakamura, S., Shirakawa, H., Nakagawa, T., and Kaneko, S. (2012). Acute cold hypersensitivity characteristically induced by oxaliplatin is caused by the enhanced responsiveness of TRPA1 in mice. Mol. Pain 8:55.

Zheng, J. (2013). Molecular mechanism of TRP channels. Compr. Physiol. 3, 221-242.

Zurborg, S., Yurgionas, B., Jira, J. A., Caspani, O., and Heppenstall, P. A. (2007). Direct activation of the ion channel TRPA1 by Ca2+. Nat. Neurosci. 10, 277-279. doi: $10.1038 / \mathrm{nn} 1843$

Conflict of Interest: The authors declare that the research was conducted in the absence of any commercial or financial relationships that could be construed as a potential conflict of interest.

Copyright (c) 2020 Roh, Go, Park, Kim and Park. This is an open-access article distributed under the terms of the Creative Commons Attribution License (CC BY). The use, distribution or reproduction in other forums is permitted, provided the original author(s) and the copyright owner(s) are credited and that the original publication in this journal is cited, in accordance with accepted academic practice. No use, distribution or reproduction is permitted which does not comply with these terms. 